\title{
Effects of Self-Education on Patient Safety via Smartphone Application for Self-Efficacy and Safety Behaviors of Inpatients in Korea
}

\author{
Sumi Cho ${ }^{1}$, Eunjoo Lee ${ }^{2}$ \\ 'Department of Nursing, Korea Nazarene University, Cheonan, Korea \\ ${ }^{2}$ College of Nursing, Research Institute of Nursing Science, Kyungpook National University, Daegu, Korea
}

Objectives: This study aimed to determine whether self-educational intervention on patient safety via a smartphone application could improve the level of self-efficacy and safety behaviors of patients. In addition the effect of change in self-efficacy on the improvement of safety behaviors after self-educational intervention was investigated. Methods: A one-group pre- and post-test design and convenience sampling were implemented. Self-educational intervention via smartphone application was provided to 94 participants in a tertiary university hospital in South Korea. The smartphone application included learning contents on why the participation of patients is critical in preventing hospital-acquired infections and surgery-related adverse events during hospitalization. Paired $t$-tests and hierarchical regression analysis were conducted to assess the effect of selfeducational intervention and self-efficacy on the improvement of safety behaviors of patients. Results: After the intervention, the level of self-efficacy and safety behaviors significantly increased from 2.53 to 2.95 and from 2.00 to 2.62 , respectively. In the hierarchical regression analysis, the change in self-efficacy accounted for $35.4 \%$ of the variance in the improvement of safety behaviors. Conclusions: The results of this study demonstrated that self-education on patient safety via a smartphone application was an effective strategy to enhance patients' self-efficacy and safety behaviors. This process could ultimately enhance patient safety by promoting patient involvement during hospitalization and preventing the occurrence of medical errors.

Keywords: Patient Participation, Patient Safety, Self-Efficacy, Mobile Applications, Education

Submitted: June 24, 2020

Revised: October 9, 2020

Accepted: December 22, 2020

\section{Corresponding Author}

Eunjoo Lee

College of Nursing, Research Institute of Nursing Science, Kyungpook National University, 680 Gukchaebosang-ro, Jung-gu, Daegu 41944, Korea. Tel: +82-53-420-4934, E-mail: jewelee@knu.ac.kr (https://orcid.org/0000-0002-6548-5593)

This is an Open Access article distributed under the terms of the Creative Commons Attribution Non-Commercial License (http://creativecommons.org/licenses/by$\mathrm{nc} / 4.0 /$ ) which permits unrestricted non-commercial use, distribution, and reproduction in any medium, provided the original work is properly cited.

(c) 2021 The Korean Society of Medical Informatics

\section{Introduction}

Recently, interest in patient involvement in their own care has considerably increased to improve patient safety because patients could play a critical role in decreasing medical errors [1]. Patients could participate in and contribute to the prevention of medical errors and adverse events in several stages of their care during hospitalization. Thus, many organizations for patient safety are leading campaigns on patient involvement, and researchers are developing interventions to educate patients so that they can play an active role in improving their own safety. For example, the "Speak Up" initiative of the US Joint Commission, the World Health 
Organization's patient safety campaign, and the "Ask Me 3" educational program of the National Patient Safety Foundation are representative examples [2,3].

Although there is high interest in patient involvement in the enhancement of patient safety, few previous studies have attempted to explain how to increase patient involvement and what factors influence the safety behaviors of patients [4-7]. Moreover, only limited studies have tried to explain patient involvement in the field of patient safety using health-related theories [8-12]. According to previous studies, the lack of confidence of patients is the main barrier to their taking action to prevent medical errors; if patients feel they are unable to contribute to their own safety, they will not participate in securing their own safety during hospitalization $[5,7]$.

Luszczynska and Gunson [10] found that perceived behavioral control was significantly associated with patients' safety behaviors, such as asking staff to wash their hands before a procedure. Schwappach and Wernli [11] emphasized that the perceived behavioral control of patients is the strongest predictor of patient intention to engage in medical error prevention. Behavioral control, which indicates what behaviors will be initiated to what extent and length regardless of obstacles, is determined by the level of self-efficacy. Therefore, the self-efficacy of patients could be a significant determinant of patient involvement in promoting his/her own safety and preventing medical errors. Previous studies have reported that self-efficacy influences behavioral control of avoidance of alcohol consumption [13], smoking cessation [14], and the regular performance of physical activities, such as walking, jogging, and joining exercise classes $[15,16]$. Moreover, individuals who have higher self-efficacy perform better self-management, such as undergoing regular screening for diseases and maintaining a healthy lifestyle for chronic disease management $[17,18]$.

However, evidence of self-efficacy regarding the prevention of medical errors, such as the adoption of safety behaviors by patients, is currently extremely limited, even though it can help enhance patient involvement in medical error prevention. Additionally, data regarding interventions to improve patients' self-efficacy using smartphone applications for patient safety are also lacking. No previous study has determined whether patient safety-related self-educational interventions provided using smartphone applications could improve patients' self-efficacy and safety behaviors, thereby enhancing patient involvement in patient safety and preventing medical errors during hospitalization.

In this study, a smartphone application was developed to address safety issues, especially surgery-related adverse events, hospital-acquired infections, and medication errors, because these issues are the most prevalent adverse events in South Korea [19]. Therefore, this study aimed to determine whether the smartphone application to address patient safety issues could improve patients' self-efficacy and safety behaviors. In addition, the effect of self-efficacy on the improvement of safety behaviors of patients was also assessed.

\section{Methods}

\section{Design and Participants}

A one-group pre- and post-test design and convenience sampling were implemented in this study. Ninety-four patients from four medical-surgical units of a tertiary university hospital in a large metropolitan city in South Korea were included. The sample size was calculated for a small effect size of 0.3 , power of 0.8 , and type I error probability of 0.05 for a one-sample pre- and post $t$-test. Using the $\mathrm{G}^{*}$ Power program, the required sample size was 82 . Therefore, the sample size used had adequate power to test the hypothesis of this study. The patient eligibility criteria were the following: (1) $>20$ years of age, (2) ability to read and speak the Korean language, and (3) the ability to use a smartphone. The exclusion criteria were the following: (1) hearing and/or vision problem and (2) schedule for emergency surgery.

\section{Instrument}

To measure self-efficacy and safety behaviors, the Seniors Empowerment and Advocacy in Patient Safety (SEAPS) survey was used after permission was obtained from the author [9]. The SEAPS survey was developed using a multistep process with rigorous psychometric analysis. To develop SEAPS, interviews with patients who had experienced a medical error or preventable harm during their healthcare were initiated with a review of government- and industrypublished recommendations as well as medical and lay literature. Community focus group interviews were also implemented. It was developed based on the health belief model and included four subscales: outcome efficacy, attitudes, selfefficacy, and behaviors. Originally, the SEAPS survey was developed with 40 items; these were reduced to 21 items after a pretest and pilot testing, which confirmed that 21 items were in good agreement with the initial 40 items. With good validity, the Cronbach's alphas of the subscales, namely, outcome efficacy, attitudes, self-efficacy, and behaviors were $0.91,0.74,0.91$, and 0.79 , respectively, in the study conducted by Elder et al. [9]. 
The SEAPS survey was adopted in this work for several reasons. First, it was developed based on the direct input of patients who had experienced medical errors and preventable harm during their healthcare. Second, this tool also includes items regarding safety behaviors that patients can use as strategies to improve their safety and quality of care. Therefore, this has a good match with the purpose of this study. All items were measured using a 4-point Likert scale, with higher scores indicating higher levels of self-efficacy with regard to patient safety and higher frequency of safety behaviors.

Self-efficacy was measured using five questions on "how confident patients are actually doing these five tasks," and safety behavior was measured using six questions on "how often patients are doing these six tasks." The Cronbach's alphas of self-efficacy and safety behavior were 0.81 and 0.89 , respectively.

The demographic variables measured were age, sex, education level, and number of previous hospitalizations. The education level was collapsed into four categories: elementary school or lower, middle school, high school, and college or higher. When the participants answered "Yes" to the question on previous hospitalization, they were asked about the number of previous hospitalizations.

\section{Ethical Considerations}

The entire content of the smartphone application and research process and the participants' information statement and informed consent were reviewed and approved by the Kyungpook National University Ethics Committee (No. 2014-0026). All specific identifiers of the participants were removed. Data were maintained anonymously and securely stored in locked files in password-protected computers.

\section{Data Collection}

The data were collected from March to June 2015. After approval was obtained from the Institutional Review Board, the researcher contacted the hospital manager and visited the hospital. The researcher explained the purpose of the study to the head nurses in the four medical-surgical units and obtained permission from the head nurse for data collection from patients admitted in their units. The research assistant met with the patients admitted to these units and explained the purpose and process of this study to them. The participants were again informed of the specific purpose of this study, procedures, and their right to withdraw at any time during the research process. The research assistants installed the smartphone application on the participants' smartphones and provided instructions on how to use the application.

First, the participants were asked to select the "Yes" option in the smartphone application if they wanted to participate in the study. Then, they were asked to complete the online pretest questionnaire via the smartphone application, which included (1) demographic characteristics, (2) items on selfefficacy in relation to patient safety, and (3) items on safety behaviors. After using the educational smartphone application for 3 days, the participants were asked to complete the posttest questionnaire, which included the same items, except the questions on demographics. The participants did not receive any compensation for their participation.

\section{Intervention}

The smartphone application used in this study included learning contents on the importance of patient involvement in patient safety and what patients have to do to prevent adverse events related to hospital-acquired infections, surgeryrelated adverse events, medication errors, falls, and so forth. The developmental process of the smartphone application for patient safety education has been previously published [20].

Patients who were willing to use the smartphone application and agreed to participate in the study by clicking the "Yes" button in the smartphone application were asked to complete the pretest questionnaire. The participants received instructions from the research assistants on how to use the smartphone application to acquire information on patient safety issues. They used the application for 3 days during their hospitalization. The educational content on patient safety is shown in Table 1.

On the first day, the participants were encouraged to access the introduction to patient safety, an explanation of the importance of patient involvement in patient safety, and ten tips to improve patient safety. Media reports on medical errors substantiated with video clips and animations were provided via the smartphone application to capture the participants' attention and increase their awareness of the risk of adverse events during hospitalization.

On the second day, the participants were encouraged to review the contents on how patients could participate in and cooperate with clinicians in preventing adverse events. The content included what patients should ask their healthcare providers during hospitalizations to enhance their own safety and what they should know about their condition. For example, the smartphone application provided questions that patients should ask their clinicians and what they should know about their medications. Moreover, the partici- 
Table 1. Self-education contents on patient safety of smartphone application

\begin{tabular}{|c|c|}
\hline Time & Self-education contents on patient safety of smartphone application \\
\hline \multirow[t]{3}{*}{ Pre-test } & Demographic characteristics \\
\hline & Self-efficacy in relation to patient safety \\
\hline & Safety behaviors \\
\hline \multirow[t]{5}{*}{ 1st day } & Introduction of patient safety \\
\hline & Importance of patient involvement in patient safety \\
\hline & Ten tips to improve patient safety \\
\hline & Major adverse events in healthcare settings \\
\hline & Media reports on medical errors \\
\hline \multirow[t]{4}{*}{ 2nd day } & Information on what patients should do and what clinicians are doing to prevent medical errors \\
\hline & What patients should ask their healthcare providers during hospitalizations \\
\hline & Customized information according to their condition \\
\hline & "Surgery", "medication", "mobility", and "catheter care” for more detailed information \\
\hline \multirow[t]{2}{*}{ 3rd day } & Review of the previous day's learning contents \\
\hline & True/false quiz questions to reinforce learning \\
\hline \multirow[t]{2}{*}{ Post-test } & Self-efficacy in relation to patient safety \\
\hline & Safety behaviors \\
\hline
\end{tabular}

\begin{tabular}{|l|l|} 
What to ask clinicians \\
What to know at discharge \\
What to do before surgery
\end{tabular}

Figure 1. Captured image of customized information icons on the smartphone application. pants could select a customized information menu according to their condition with submenus: "surgery", "medication", "mobility", and "catheter care" for more detailed information (Figure 1).

On the third day, the participants reviewed the previous day's learning content and took a true/false quiz to reinforce learning. The research assistants asked the participants if they had reviewed the daily learning content of the smartphone application and encouraged them to review the contents. The amount of time each participant spent using the smartphone application for self-education was not limited. After using the self-education smartphone application for 3 days, the participants completed the posttest questionnaire with the help of the research assistants.

\section{Data Analysis}

The participants' demographic data were analyzed in terms of percentages and frequencies. Paired $t$-tests were used to analyze the differences between the baseline and posttest scores. Hierarchical regression analysis was used to identify the factors influencing improvement in safety behaviors. For the assumptions of the multiple linear regression analysis, residual autocorrelation was tested with the Durbin-Watson statistic, and no autocorrelation existed. A $p$-value $<0.05$ was considered to be statistically significant. Analyses were conducted using the SPSS version 20.0 (IBM, Armonk, NY, USA) software for Windows.

\section{Results}

\section{Participants}

A total of 110 patients admitted to the medical-surgical units expressed interest in participating in this study, of whom 99 participants consented to participate by signing the written consent form and completing the questionnaire. Two participants discontinued intervention, and three par- 
ticipants could not be complete the post-test because they were discharged. Eventually, the data from 94 participants were analyzed. The average age of the participants was $45 \pm$ 12.8 years. Almost half of them (43.6\%) had completed college education or education higher than college level, and

Table 2. Demographic characteristics of the participants $(n=94)$

\begin{tabular}{|c|c|}
\hline Variable & Value \\
\hline Age (yr) & $45.0 \pm 12.8$ \\
\hline$<40$ & $32(34.0)$ \\
\hline $40-59$ & $22(23.4)$ \\
\hline $60-69$ & $29(30.9)$ \\
\hline$\geq 70$ & $11(11.7)$ \\
\hline \multicolumn{2}{|l|}{ Sex } \\
\hline Female & $55(58.5)$ \\
\hline Male & $39(41.5)$ \\
\hline \multicolumn{2}{|l|}{ Education } \\
\hline Elementary & $2(2.1)$ \\
\hline Middle & $6(6.4)$ \\
\hline High & $40(42.6)$ \\
\hline$\geq$ College & $41(43.6)$ \\
\hline No answer & $5(6.3)$ \\
\hline \multicolumn{2}{|c|}{ Number of previous hospitalizations } \\
\hline 0 & 39 (41.5) \\
\hline 1 & $8(8.5)$ \\
\hline 2 & $30(31.9)$ \\
\hline$\geq 3$ & $13(13.8)$ \\
\hline No answer & $4(4.3)$ \\
\hline
\end{tabular}

Values are presented as mean \pm standard deviation or number (\%).
$42.6 \%$ had completed high school. A total of $58.5 \%$ of the participants were female; $41.5 \%$ had never been hospitalized, whereas the rest had previously been admitted to the hospital one or more times. These findings are shown in Table 2.

\section{Differences in Self-Efficacy Level and Safety Behaviors Before and After Intervention}

The mean level of self-efficacy increased from $2.53 \pm 0.49$ to $2.95 \pm 0.61$ after self-education intervention on patient safety using the smartphone application $(t=-7.28, p<0.001)$. As shown in Table 3, the scores for all subscales in self-efficacy showed improvement, and there were statistically significant differences between the pre- and posttest scores.

Moreover, the result showed that the mean score of safety behaviors also significantly increased from $2.00 \pm 0.67$ to $2.62 \pm 0.76$, and there were significant improvements in all subscales of safety behaviors after self-education on patient safety via the smartphone application $(t=-8.62, p<0.001)$ (Table 4).

\section{Factors Influencing Improvement in Safety Behaviors}

Demographic characteristics, including age, sex, education level, and the number of hospitalizations, as well as change in self-efficacy score, were evaluated using hierarchical regression analysis to investigate the influence on improvement in safety behaviors (Table 5). The variables' categories of sex and education level were converted into dummy variables. The Durbin-Watson statistic was equal to 1.71, and it indicated that there was no autocorrelation problem between the residual amounts. The variance inflation factors for independent variables were calculated for collinearity diagnosis, and they were between 1.01 and 1.50, which indicated that

Table 3. Differences in self-efficacy levels before and after intervention

\begin{tabular}{|c|c|c|c|c|}
\hline Questions & Before & After & $t$ & $p$-value \\
\hline $\begin{array}{l}\text { 1. How confident are you that you could teach yourself about your own } \\
\text { health problems and medications? }\end{array}$ & $2.40 \pm 0.78$ & $2.80 \pm 0.82$ & -4.58 & $<0.001$ \\
\hline $\begin{array}{l}\text { 2. How confident are you that you could call the doctor's office if you } \\
\text { have not received the results of laboratory tests or X-rays? }\end{array}$ & $2.68 \pm 0.82$ & $3.02 \pm 0.80$ & -3.23 & 0.002 \\
\hline $\begin{array}{l}\text { 3. How confident are you that you could obtain a second opinion from } \\
\text { another doctor if you think it is needed? }\end{array}$ & $2.50 \pm 0.85$ & $2.94 \pm 0.89$ & -4.97 & $<0.001$ \\
\hline $\begin{array}{l}\text { 4. How confident are you that you could provide your doctors a com- } \\
\text { plete and thorough summary of your health problems? }\end{array}$ & $2.63 \pm 0.77$ & $3.04 \pm 0.73$ & -4.67 & $<0.001$ \\
\hline $\begin{array}{l}\text { 5. How confident are you that you could ask a friend or family member } \\
\text { to come with you to doctor visits? }\end{array}$ & $2.45 \pm 0.81$ & $2.94 \pm 0.84$ & -5.06 & $<0.001$ \\
\hline Mean of the five questions & $2.53 \pm 0.49$ & $2.95 \pm 0.61$ & -7.28 & $<0.001$ \\
\hline
\end{tabular}

Values are presented as mean \pm standard deviation. 
Table 4. Differences in safety behaviors before and after intervention

\begin{tabular}{|c|c|c|c|c|}
\hline Questions & Before & After & $t$ & $p$-value \\
\hline 1. How often do you teach yourself about your own health problems and medicines? & $2.19 \pm 0.88$ & $2.72 \pm 0.80$ & -5.58 & $<0.001$ \\
\hline $\begin{array}{l}\text { 2. How often do you ask your doctors questions about your health problems, labo- } \\
\text { ratory tests, and medications? }\end{array}$ & $2.27 \pm 0.83$ & $2.77 \pm 0.89$ & -5.60 & $<0.001$ \\
\hline $\begin{array}{l}\text { 3. How often do you keep an updated list of all your medicines, including those } \\
\text { from the drug store and health food store? }\end{array}$ & $1.65 \pm 0.97$ & $2.39 \pm 1.03$ & -6.83 & $<0.001$ \\
\hline $\begin{array}{l}\text { 4. How often do you call the doctor's office if you have not received the results of } \\
\text { laboratory tests or X-rays? }\end{array}$ & $1.86 \pm 0.91$ & $2.59 \pm 0.97$ & -8.27 & $<0.001$ \\
\hline 5. How often do you obtain a second opinion from another doctor when needed? & $2.11 \pm 1.00$ & $2.60 \pm 0.99$ & -4.78 & $<0.001$ \\
\hline 6. How often do you ask a friend or family member to come with you to doctors' visits? & $1.97 \pm 0.93$ & $2.65 \pm 0.99$ & -6.17 & $<0.001$ \\
\hline Mean of the six questions & $2.00 \pm 0.67$ & $2.62 \pm 0.76$ & -8.62 & $<0.001$ \\
\hline
\end{tabular}

Values are presented as mean \pm standard deviation.

Table 5. Factors influencing improvement in safety behaviors

\begin{tabular}{|c|c|c|c|c|c|}
\hline Model & Variable & $\begin{array}{c}\text { Unstandardized } \\
\text { coefficient B }\end{array}$ & Stand error & $\begin{array}{c}\text { Stand coefficient } \\
\text { beta }\end{array}$ & $t$ ( $p$-value) \\
\hline \multirow[t]{9}{*}{ Model 1} & Constant & 0.76 & 0.31 & - & $2.43(0.017)$ \\
\hline & Age (yr) & 0.00 & 0.01 & 0.02 & $0.14(0.886)$ \\
\hline & Sex $($ male $=1)$ & -0.73 & 0.17 & -0.05 & $-0.44(0.662)$ \\
\hline & Education (college or higher $=1$ ) & & & & \\
\hline & Elementary or none & -0.10 & 0.58 & -0.02 & $-0.16(0.874)$ \\
\hline & Middle school & 0.11 & 0.34 & 0.04 & $0.31(0.757)$ \\
\hline & High school & 0.21 & 0.18 & -0.15 & $-1.15(0.253)$ \\
\hline & Number of previous hospitalizations & -0.06 & 0.07 & -0.10 & $-0.90(0.371)$ \\
\hline & & \multicolumn{4}{|c|}{$F=0.44, p=0.85, \mathrm{R}^{2}=0.03$, adjusted $\mathrm{R}^{2}=-0.04$} \\
\hline \multirow[t]{10}{*}{ Model 2} & Constant & 0.50 & 0.25 & - & $1.90(0.061)$ \\
\hline & Age (yr) & -0.00 & 0.01 & -0.07 & $-0.64(0.523)$ \\
\hline & Sex $($ male $=1)$ & -0.12 & 0.13 & -0.08 & $-0.90(0.373)$ \\
\hline & Education (college or higher $=1$ ) & & & & \\
\hline & Elementary or none & -0.05 & 0.45 & -0.01 & $-0.10(0.922)$ \\
\hline & Middle school & 0.02 & 0.27 & 0.01 & $0.08(0.938)$ \\
\hline & High school & 0.05 & 0.15 & 0.04 & $0.36(0.723)$ \\
\hline & Number of previous hospitalizations & -0.00 & 0.06 & -0.01 & $-0.05(0.960)$ \\
\hline & Change in self-efficacy & 0.83 & 0.12 & 0.65 & $7.15(<0.001)$ \\
\hline & & \multicolumn{4}{|c|}{$F=7.90, p<0.001, \mathrm{R}^{2}=0.41$, adjusted $\mathrm{R}^{2}=0.35$} \\
\hline
\end{tabular}

multicollinearity was negligible. The first model including demographic variables, age, sex, education level, and number of previous hospitalizations, was not significant. When the change in self-efficacy score between the baseline and posttest scores was additionally included, the result showed that the prediction model was significant $(F=7.929, p<0.001)$. The change in self-efficacy accounted for $35.4 \%\left(R^{2}=0.406\right.$, adjusted $\left.R^{2}=0.354\right)$ of the variance in the improvement of safety behaviors.

\section{Discussion}

This study assessed the effects of self-education on patient safety issues via a smartphone application on the improve- 
ment of patients' self-efficacy and safety behaviors and investigated the factors influencing the improvement of safety behaviors. The findings of this study indicate that patients' self-efficacy and safety behaviors could be enhanced by selfeducation on patient safety using a smartphone application. This study also revealed that change in self-efficacy was the most important attribute of safety behavior improvement.

Schwappach et al. [21] provided advice on the admission of patients and asked them to follow the recommendations. Additionally, healthcare workers and clinical staff were asked to participate in lessons and information meetings to prepare them for patient's questions on safety issues. However, in the study conducted by Schwappach et al. [21], the performance of safety behaviors of patients was not improved after the safety advisory interventions by clinicians. This study provided real media reports on medical errors and major adverse events occurring during hospitalization, which might be used as triggers to accept recommended safety behaviors by the participants. Real stories of medical errors and adverse events could gain more attention of patients on safety behaviors to prevent medical errors.

The health belief model posits that a "cue to action" is necessary to prompt engagement in health behaviors [22]. Participants in this study were presented medical errors from media reports via the smartphone application, which might function as external cues to safety behavior and could stimulate participants to take action and influenced their selfefficacy [8]. Moreover, providing the educational content, including what to do and what to know to prevent adverse events, which might occur in patients, could improve participants' self-efficacy.

In this study, the mean scores of both self-efficacy and safety behaviors showed significant increases from 2.53 to 2.95 and from 2.00 to 2.62 , respectively. Therefore, self-education on patient safety issues via the smartphone application could be an effective and efficient strategy for enhancing the selfefficacy and safety behaviors of patients. Self-efficacy on patient safety was defined as an individual's perception of his/ her competence to successfully improve patient safety.

In this study, the level of self-efficacy was comparatively higher than that reported in the study by Elder et al. [9], who had adopted the same instrument. In their study, the mean self-efficacy score was 1.6. This discrepancy may have been caused by differences in participants' ages and the settings adopted for data collection. The mean age in the present study was 45 years, and the study participants were hospitalized, whereas the mean age in the study by Elder et al. [9] was 70 years, and participants were community-dwelling individuals.

In this study, the predictive power of the change in self-efficacy in relation to the improvement of safety behaviors was $35.4 \%$. Previous studies also reported that self-efficacy could influence safety behaviors and resulted in increased patient involvement and prevention of medical errors during hospitalization $[8,23]$. However, these studies did not examine the effect of education on safety efficacy and safety behavior improvement. This study controlled the baseline of self-efficacy and examined the variables associated with changes in selfefficacy from baseline to post-intervention. The important finding of this study is that even patients who have low selfefficacy on patient safety could improve their patient safety behaviors through self-education using their smartphones by enhancing their self-efficacy. Therefore, effective educational interventions to enhance the self-efficacy of patients is critically needed to encourage patient involvement to prevent medical errors during hospitalization.

To increase awareness of patient safety during hospitalization, many patient education strategies are implemented using information leaflets and posters. However, according to a previous study, patients often fail to acquire new information on patient safety, and between $40 \%$ and $80 \%$ of the information is immediately forgotten because the primary concern of patients is their illness, not safety-related issues [24]. Thus, development of different strategies, such as the use of a smartphone application, is needed to prevent patients from getting lost in the myriad of information made available by healthcare providers.

Smartphones are easily accessible and can provide the required information whenever and wherever necessary during hospitalization [25]. As patients' awareness of potential risks increases, patients could be more involved and try to engage in safety behaviors to prevent potential medical errors. Therefore, nurses and healthcare professionals need to provide appropriate information to patients on safety issues during hospitalization and the roles every patient can play in preventing medical errors [26].

Schwappach and Wernli [11] analyzed patients receiving chemotherapy in a large regional hospital for their attitudes, norms, behavioral control, and intentions to engage in safety behavior. In their study, the mean scores of instrumental and experimental attitudes were 5.49 and 4.11, respectively, and the mean scores of behavioral control and intention to prevent medical errors were 5.24 and 5.36, respectively, as measured on a 7-point Likert scale, and the mean age of participants was 61 years. These scores were higher than those observed in this study. This may be attributed to the fact 
that chemotherapy requires increased attention of patients, and patients should be aware of the potential risks induced by chemotherapy because its outcome could occasionally be life-threatening.

Previous studies have shown that younger patients are more willing to be involved in safety issues than older patients [27], and patients who have higher education levels are more active than those with lower education levels $[8,27]$. However, in this study, there were no significant associations between the improvement in safety behaviors and participants' sociodemographic factors, such as sex, education level, age, and previous hospitalization. This can be attributed to the high education level of the participants in this study; specifically, almost half of the patients (43.6\%) had education levels of college or higher and comparatively young age. Therefore, using a more controlled study design, further investigation is needed to understand why sociodemographic factors, such as sex, educational level, and age, were not related to safety behaviors in this study.

This study had several limitations. First, convenience sampling was used to recruit participants from only one academically affiliated tertiary hospital in South Korea, limiting the generalizability of the results beyond this setting. Thus, further research is required to confirm the findings of this study. Second, the instrument used in the study to test patients' self-efficacy in relation to patient safety and safety behaviors was developed for senior citizens in a Western country; thus, this may limit the validity of the study. Third, this study only examined self-efficacy; it did not include other possible factors, such as perceived susceptibility, perceived barriers, and cues to safety behaviors. In further studies, these variables need to be included to identify the specific impact of self-efficacy and other factors and effects of interaction among these variables. Finally, this study only measured the self-efficacy and safety behaviors of participants after 3 consecutive days; therefore, it is strongly recommended to examine the changes in safety behaviors of participants after 3 or 6 months because actual changes in behaviors need more time.

In conclusion, the results of this study showed that selfeducational intervention via a smartphone application is an effective strategy to enhance patients' self-efficacy and safety behaviors. This process could ultimately enhance patient safety by promoting patient involvement during hospitalization and preventing the occurrence of medical errors. The current international policy suggests that increased patient involvement in safety issues could help prevent medical errors. Even though self-efficacy has been reported to be an important predictor for the promotion of health behaviors, the evidence of self-efficacy with regard to the implementation of safety behaviors to prevent medical errors by patients is extremely limited. Therefore, the importance of patients self-efficacy should be considered by both healthcare professionals and nurses, and diverse strategies to enhance the selfefficacy of patients should be developed in future studies.

\section{Conflict of Interest}

No potential conflict of interest relevant to this article was reported.

\section{Acknowledgments}

This work was supported by the National Research Foundation of Korea of the Ministry of Education of the Republic of Korea (No. NRF-2015S1A5A2A01009760).

\section{ORCID}

Sumi Cho (https://orcid.org/0000-0001-6622-243X)

Eunjoo Lee (https://orcid.org/0000-0002-6548-5593)

\section{References}

1. Vincent CA, Coulter A. Patient safety: what about the patient? BMJ Qual Saf 2002;11(1):76-80.

2. Entwistle VA, Mello MM, Brennan TA. Advising patients about patient safety: current initiatives risk shifting responsibility. Jt Comm J Qual Patient Saf 2005; 31(9):483-94.

3. Longtin Y, Sax H, Leape LL, Sheridan SE, Donaldson L, Pittet D. Patient participation: current knowledge and applicability to patient safety. Mayo Clin Proc 2010; 85(1):53-62.

4. Buetow S, Davis R, Callaghan K, Dovey S. What attributes of patients affect their involvement in safety? A key opinion leaders' perspective. BMJ Open 2013;3(8): e003104.

5. Davis RE, Jacklin R, Sevdalis N, Vincent CA. Patient involvement in patient safety: what factors influence patient participation and engagement? Health Expect 2007;10(3):259-67.

6. Doherty C, Stavropoulou C. Patients' willingness and ability to participate actively in the reduction of clinical errors: a systematic literature review. Soc Sci Med 2012; 75(2):257-63. 
7. Hall J, Peat M, Birks Y, Golder S, Entwistle V, Gilbody S, et al. Effectiveness of interventions designed to promote patient involvement to enhance safety: a systematic review. Qual Saf Health Care 2010;19(5):e10.

8. Bishop AC, Baker GR, Boyle TA, MacKinnon NJ. Using the Health Belief Model to explain patient involvement in patient safety. Health Expect 2015;18(6):3019-33.

9. Elder NC, Regan SL, Pallerla H, Levin L, Post D, Cegela DJ. Development of an instrument to measure seniors' patient safety health beliefs: the Seniors Empowerment and Advocacy in Patient Safety (SEAPS) survey. Patient Educ Couns 2007;69(1-3):100-7.

10. Luszczynska A, Gunson KS. Predictors of asking medical personnel about handwashing: the moderating role of patients' age and MRSA infection status. Patient Educ Couns 2007;68(1):79-85.

11. Schwappach DL, Wernli M. Predictors of chemotherapy patients' intentions to engage in medical error prevention. Oncologist 2010;15(8):903-12.

12. Schwappach DL. Engaging patients as vigilant partners in safety: a systematic review. Med Care Res Rev 2010;67(2):119-48.

13. Oei TP, Burrow T. Alcohol expectancy and drinking refusal self-efficacy: a test of specificity theory. Addict Behav 2000;25(4):499-507.

14. Baldwin AS, Rothman AJ, Hertel AW, Linde JA, Jeffery RW, Finch EA, et al. Specifying the determinants of the initiation and maintenance of behavior change: an examination of self-efficacy, satisfaction, and smoking cessation. Health Psychol 2006;25(5):626-34.

15. Shafieian M, Kazemi A. A randomized trial to promote physical activity during pregnancy based on health belief model. J Educ Health Promot 2017;6:40.

16. Shao C, Wang J, Liu J, Tian F, Li H. Effect of a Health Belief Model-based education program on patients' belief, physical activity, and serum uric acid: a randomized controlled trial. Patient Prefer Adherence 2018;12:123945.
17. Shin DS, Kim CJ, Choi YJ. Effects of an empowerment program for self-management among rural older adults with hypertension in South Korea. Aust J Rural Health 2016;24(3):213-9.

18. Wichit N, Mnatzaganian G, Courtney M, Schulz P, Johnson M. Randomized controlled trial of a familyoriented self-management program to improve selfefficacy, glycemic control and quality of life among Thai individuals with type 2 diabetes. Diabetes Res Clin Pract 2017;123:37-48.

19. Kim NY. Analysis of patient safety incident in Korea. J Korean Acad Nurs Adm 2016;26(2):151-9.

20. Cho S, Lee E. Effects of the smartphone application "Safe Patients" on knowledge of patient safety issues among surgical patients. Comput Inform Nurs 2017;35(12):63946.

21. Schwappach DL, Frank O, Buschmann U, Babst R. Effects of an educational patient safety campaign on patients' safety behaviours and adverse events. J Eval Clin Pract 2013;19(2):285-91.

22. Carpenter CJ. A meta-analysis of the effectiveness of health belief model variables in predicting behavior. Health Commun 2010;25(8):661-9.

23. Hibbard JH, Peters E, Slovic P, Tusler M. Can patients be part of the solution? Views on their role in preventing medical errors. Med Care Res Rev 2005;62(5):601-16.

24. Shankar J. Patients' memory for medical information. J R Soc Med 2003;96(10):520.

25. Dennison L, Morrison L, Conway G, Yardley L. Opportunities and challenges for smartphone applications in supporting health behavior change: qualitative study. J Med Internet Res 2013;15(4):e86.

26. Vaismoradi M, Jordan S, Kangasniemi M. Patient participation in patient safety and nursing input: a systematic review. J Clin Nurs 2015;24(5-6):627-39.

27. Arora NK, McHorney CA. Patient preferences for medical decision making: who really wants to participate? Med Care 2000;38(3):335-41. 